\title{
O lado escuro da força: a ditadura militar e o curso de história da Faculdade Nacional de Filosofia da Universidade do Brasil (FNFi/UB)
}

\author{
The dark side of the force: the military dictatorship and the history course \\ of the National School of Philosophy of the University of Brazil (FNFi/UB)
}

\author{
Marieta de Moraes Ferreira \\ Marieta.Moraes@fgv.br \\ Professora associada \\ Universidade Federal do Rio de Janeiro \\ Praia de Botafogo, 190/140 andar - Botafogo \\ 22253-900 - Rio de Janeiro - RJ \\ Brasil
}

\section{Resumo}

A proposta deste artigo é focalizar os últimos anos da existência do curso de história da FNFi/ UB (1958-1968), com vistas a recuperar os embates políticos e historiográficos aí travados, e entender o percurso desse campo disciplinar e seu processo de profissionalização, num momento de grandes transformações. Estão igualmente contempladas as discussões relativas a problemáticas que caracterizam as memórias de eventos traumáticos e a história do tempo presente. Para isto foram consultadas diferentes tipos de fontes como depoimentos orais, jornais, documentos da FNFi, arquivos policiais.

\section{Palavras-chave}

Ensino de história; Ditadura militar; Faculdade Nacional de Filosofia/Universidade do Brasil.

\begin{abstract}
The aim of this article is to focus on the final years of the course of history at the FNFi/UB (1958-1968), in order to recover the political and historiographical conflicts that took place there, and to understand the trajectory of this disciplinary field and its professionalizationprocess at a moment of great transformations. The article's coverage extends to the discussions related to the issues that characterize the memories of traumatic events and the History of the Present Time. Different types of sources were used, such as oral statements, newspapers, FNFi documents, and police archives.
\end{abstract}

\section{Keywords}

History teaching; Military dictatorship; Faculdade Nacional de Filosofia/Universidade do Brasil.

Enviado em: 20/1/2013

Aprovado em: 4/3/2013 
Nos últimos tempos, têm sido crescentes os debates acerca do papel social dos historiadores e sobre em que medida a história universitária deve estar sintonizada com as demandas sociais, e como a comunidade acadêmica deve evitar seu isolamento e sua omissão e ter o compromisso de transpor seus conhecimentos para o grande público e para a educação básica. Essas questões têm suscitado muitas outras perguntas, na medida em que as instituições e os atores sociais buscam, muitas vezes, por meio da história, a legitimação de seus pontos de vista. As demandas sociais podem colocar em risco a autonomia da história como disciplina científica? A pressão do dever de memória pode criar problemas graves para as práticas profissionais do historiador?

Esses desafios se manifestam especialmente no estudo da história do tempo presente, que, durante muito tempo, foi objeto de resistências e interdições, mas entrou na ordem do dia no Brasil, em virtude da instalação da Comissão da Verdade, destinada a apurar crimes contra os direitos humanos, não só como objeto de pesquisa acadêmica, mas também como um tema desafiador para os historiadores do ponto de vista ético e político. Qual a postura que a comunidade científica deve adotar? Ela deve se envolver diretamente nesse debate? Em caso afirmativo, que regras devem nortear sua postura? Esse envolvimento institucional não acaba por atribuir ao historiador o papel de juiz da história?

Nesse contexto, os historiadores que trabalham com a história do tempo presente são instados a enfrentar esse desafio e a aproveitar a oportunidade para ampliar e legitimar seu campo de estudos, mas também precaver-se das pressões indevidas das demandas sociais e da obrigatoriedade do dever de memória.

Se a história efetua realmente um trabalho crítico em relação à memória, a mesma permite ao historiador superar uma visão puramente retrospectiva do passado e entender como o presente impacta essa leitura do passado. Esse conjunto de problemas levantados indica uma forte tensão sobre o papel social do historiador, ou dito de outra forma, como fazer uma história pública e garantir o respeito às práticas científicas da história?

Outro exemplo concreto das tensões enfrentadas pelo profissional de história manifesta-se no momento presente, por meio do debate sobre a regulamentação do ofício do historiador. Com a aprovação do projeto no Senado, que agora caminha para a Câmara dos Deputados, inúmeras têm sido as críticas a ele feitas por parte da mídia e de profissionais de outras áreas, mas que trabalham no campo da história.

O projeto de lei n 368/09 prevê que a profissão de historiador deve ser exercida por diplomados em cursos de graduação, mestrado ou doutorado em história. Por exercício da profissão, entende-se a atuação como professores de história da educação básica e do ensino superior e o "planejamento, organização, implantação e direção de serviços de pesquisa histórica" (artigo 4, inciso III), além do "assessoramento voltado à avaliação e seleção de documentos para fins de preservação" (artigo 4, inciso V). Assim, fica definido que a profissão de historiador, englobando pesquisa e ensino, não pode ser exercida por aqueles que não obtiveram diploma em cursos de graduação, mestrado ou doutorado em história. 
As discussões sobre os objetivos da regulamentação têm sido intensas. Entre os contrários à regulamentação, há dois grupos: os que são contra toda e qualquer regulação profissional, e os que se opõem especificamente à criação da profissão de historiador, uma vez que esse conhecimento específico poderia ser adquirido de outras maneiras que não a formação universitária (GRIMBERG 2012). Em contra partida, a Associação Nacional dos Professores Universitários de História (Anpuh) tem defendido a necessidade da regulamentação e as especificidades para a produção do conhecimento histórico. Todas essas questões, em pauta na atualidade, nos estimulam a refletir não só sobre o lugar da história hoje, mas também a compreender o percurso que este campo de conhecimento percorreu nos nosso país, a partir do processo de profissionalização universitária, iniciado nos anos 1930, quando as denominações professor e historiador representavam coisas muito distintas. ${ }^{1}$

Os primeiros cursos de história estavam sendo criados para formar professores que deveriam atuar na educação básica, ou secundariamente na educação superior. A atividade de pesquisa, dependendo do curso, poderia ser mais ou menos desenvolvida, mas estava longe de ser o foco principal. Assim, o indivíduo responsável pela escrita da história, o historiador, não estava associado e envolvido diretamente com a docência, ou, se atuava como professor, não era sua meta levar os alunos a desenvolverem pesquisas. Este papel estava reservado a profissionais liberais eruditos que praticavam a pesquisa como uma atividade paralela nas suas vidas. Na atualidade, essa situação foi substancialmente alterada, com a criação dos programas de pós-graduação, a partir dos anos 1970, que, anualmente, formam centenas de mestres e doutores que, na maioria dos casos, reúnem recursos para exercer atividades de pesquisa e de ensino. Assim, cada vez mais, a denominação "historiador", que, no passado, referia-se apenas aos que escreviam história, passa a abarcar aqueles que recebem uma titulação específica, seja para a docência, seja para a pesquisa.

A proposta deste artigo, de focalizar os últimos anos da existência do curso de história da FNFi/UB (1958-1968) e os embates aí travados, desperta grande interesse e oferece possibilidades teóricas e metodológicas para encararmos os desafios de entender o percurso desse campo disciplinar e seu processo de profissionalização, num momento de grandes transformações, bem como as problemáticas que caracterizam a história do tempo presente. Lidar com os eventos e os atores que participaram dessa história é uma oportunidade para exercitarmos nossa capacidade crítica de avaliar interpretações marcadas por memórias traumáticas, fontes policiais, periódicos fortemente comprometidos

\footnotetext{
${ }^{1}$ Ainda que alguns trabalhos como os de Manoel Salgado destaquem a relevância da produção do IHGB e caracterize esses autores como profissionais de história é preciso chamar a atenção para a distinção entre aqueles e uma nova categoria de profissionais que começam a surgir a com a da criação dos cursos universitários na década de 1930, que recebem uma formação especifica, voltada para a preparação para atividade docente. Ainda que se reconheça o valor da produção e a identidade de historiadores profissionais vinculados ao IHGB ao longo do século XIX e na Primeira República, a sua grande maioria não estava dedicado ao ensino e não estava focada em formar professores. Além disso, embora fossem intelectuais produtores de obras de grande relevância, podem ser considerados como autodidatas, já que não tiveram uma formação disciplinar especifica para atuarem como professores de história . Para um aprofundamento sobre a criação de campos disciplinares ver: BOUTIER; REVEL 2006.
} 
com posicionamentos ideológicos polarizados e radicais. Portanto, este artigo insere-se nessa orientação de analisar as lutas políticas e a repressão que atingiu professores e alunos da FNFi, buscando produzir uma análise que possa garantir as regras de cientificidade dessa história sensível. ${ }^{2}$

Para tal, tomamos como referência um conjunto diversificado de fontes que nos permitissem recuperar eventos desse passado recente marcado pela emoção e pela subjetividade. Um ponto de partida importante para a pesquisa foi a entrevista realizada com Maria Yeda Linhares, em 1994, que serviu de roteiro inicial para, em anos posteriores, orientar a realização de outras entrevistas feitas com antigos alunos e professores. Embora produzidas em contextos e com objetivos distintos, as entrevistas têm um eixo comum que focaliza a trajetória dos depoentes, as suas origens familiares, sua formação profissional, sua opção pela área de história, a docência na FNFi, e sua experiência como alunos daquela faculdade. A escolha dos entrevistados teve um objetivo claro: obter depoimentos de ex-alunos e professores de diferentes gerações que pudessem recuperar eventos e momentos diversos do curso de história da FNFI. ${ }^{3}$

Ao lado da coleta da memória oral, o acervo da própria FNFi também forneceu material que nos ajudou a conhecer a estrutura dos cursos e as grades curriculares. Ainda que de maneira muito fragmentada e dispersa, essa documentação permitiu localizar, de maneira mais precisa, eventos, nomes e datas. Os boletins do Centro de Estudos de História foram especialmente de grande valia para mapear os conflitos políticos e historiográficos em pauta no curso de história, para os anos de 1958-1963. Por fim, de grande importância foram também os arquivos do Departamento de Ordem Política e Social (Dops), nos quais foram localizados dossiês dos professores e alunos e, em especial, um dossiê dedicado à FNFi. Esse acervo, ao mesmo tempo rico e perigoso, que exige extremo cuidado do pesquisador, reúne informações que permitem esclarecer, confrontar, questionar os dados relatados pelos depoimentos orais. Para completar esse circuito de pesquisa, matérias de alguns grandes jornais do Rio, como O Globo, Jornal do Brasil e O Jornal permitiram compreender melhor a natureza dos embates políticos então travados e a importância que a FNFi ocupava na mídia.

\section{Lutas politicas e constituição de um campo disciplinar: os anos 1950}

A Faculdade Nacional de Filosofia, e, em particular, o curso de história passariam por grandes transformações na virada dos anos 1950. Criado em 1939, vinculado à Universidade do Brasil, o projeto da Faculdade de Filosofia visava à consolidação de uma universidade-padrão que servisse de modelo para as outras que viessem a se constituir, e tinha por objetivo prioritário preparar candidatos ao magistério do ensino secundário e normal. A FNFi estava organizada em

\footnotetext{
2 Para uma aprofundamento da discussão sobre história do tempo presente, ver: FERREIRA 2011. ${ }^{3}$ Entre os entrevistados estão Vicente Tapajós, Borges Hermida e Eremildo Viana, Maria Yeda Linhares, Eulália Lobo, Cibele Ipanema Moreira; Francisco Falcon, Miridan Knox e Clóvis Dotore, Pedro Celso Uchoa Cavalcanti, Ilmar Matos, Neyde Thelm, Arno Welling, e, por fim, Nara Saleto, que não foi aluna nem professora da FNFi, mas ingressou como professora assistente no curso de história, já depois de 1968, e seu depoimento nos forneceu um olhar externo de quem chegou nos anos difíceis da repressão.
} 
quatro seções fundamentais: de Filosofia, de Ciências, de Letras e de Pedagogia. Haveria, ainda, uma seção especial de Didática. História e geografia, entre outros cursos, ligavam-se à Seção de Ciências. As formações em história e geografia foram reunidas num único curso voltado essencialmente para o ensino. O curso de história e geografia só seria desmembrado a partir de $1955 .^{4}$

Fundada durante o Estado Novo e marcada pelas ideias autoritárias, a FNFI foi fortemente influenciada por setores católicos ligados ao Centro Dom Vital, a Alceu de Amoroso Lima e a antigos integralistas que foram nomeados para ocupar postos importantes na universidade recém-criada. A direção da faculdade foi entregue a San Tiago Dantas, e a cátedra de história do Brasil, que, no contexto do Estado Novo, deveria desempenhar um papel-chave na formação dos futuros professores secundários, ficou a cargo de Hélio Viana. Assim, a institucionalização do curso de história na FNFi foi fortemente influenciada pela concepção de uma história política, dominante na época, destinada a reforçar os laços da identidade brasileira por meio da ênfase na unidade nacional e no papel dos grandes heróis como construtores da Nação (FERREIRA 2012a).

Com a queda do regime de Vargas em 1945, a FNFi passaria por algumas alterações. Foi a partir desse momento, com o processo de redemocratização, que a Universidade do Brasil teve seus contornos mais bem definidos, tanto do ponto de vista da sua concepção de ensino e pesquisa quanto de suas estruturas administrativa e financeira. Desse modo, em 1946, as escolas passariam a ser organizadas em departamentos. A FNFi passou a ter também departamentos, assim distribuídos: Filosofia, Matemática, Física, Química, História Natural, História e Geografia, Ciências Sociais, Letras e Pedagogia. A despeito dessas mudanças administrativas e da abertura de concursos para legalizar os postos de catedráticos, o curso de história e geografia não sofreu mudanças substantivas, nem na sua grade curricular nem na composição de seus professores. Em verdade, o que vemos é que professores como Eremildo Viana (história antiga e medieval), Delgado de Carvalho (história moderna e contemporânea), Silvio Júlio (história da América) e Hélio Viana (história do Brasil) foram confirmados à frente das principais cátedras.

Nos anos 1950, o curso de história começou a ocupar um lugar de maior destaque no âmbito da Faculdade Nacional de Filosofia. Depois de mais de dez anos sob a direção do Antonio Carneiro Leão, professor de Administração Escolar e Educação Comparada, Eremildo Viana assumiu, em 1958, a direção da Faculdade, apoiado pela maior parte de seus colegas. Eremildo permaneceu no cargo até 1963, tendo sido reeleito em 1960.

A partir de 1955, ocorreu a separação do curso de história e geografia em dois departamentos distintos. Essa alteração abriu espaços para uma maior oxigenação do curso de história, com uma mudança curricular e a introdução de novas disciplinas. A cadeira de introdução metodológica à história foi incorporada à grade do primeiro semestre, e disciplinas eletivas foram também disponibilizadas para os alunos. Paralelamente, uma geração mais nova de

\footnotetext{
${ }^{4}$ A primeira parte deste artigo é um resumo de outros textos publicados por Ferreira $(2006 ; 2008 a ; 2012 a)$.
} 
professores começou a ocupar posições. Ainda nesse mesmo ano, o catedrático Delgado de Carvalho se aposentou, e Maria Yedda Linhares fez concurso para ocupar a cátedra de história moderna e contemporânea. Em 1958, Eulália Lobo assumiu o posto de regente da cadeira de história da América, cujo titular ainda era Sílvio Julio de Albuquerque. Novos assistentes também passaram a ser incorporados em várias disciplinas, como Eugênia Prado, Francisco Falcon e Arthur e Hugo Weiss, na cadeira de história moderna e contemporânea, Manuel Maurício Albuquerque e Luís Werneck da Silva, ambos na cadeira de história do Brasil (FERREIRA 2012a).

\section{Um embate historiográfico: Nelson Werneck versus Helio Viana}

A conjuntura que se inaugurou no final dos anos 1950 foi marcada por um processo de radicalização dos movimentos sociais, criando uma polarização entre esquerda e direita. Delineava-se um contexto político de grande mobilização contra o comunismo e contra a Revolução Cubana. Essas questões dominantes na conjuntura internacional promoviam uma grande polarização e confronto entre os países ocidentais capitalistas e os países comunistas, e exacerbavam internamente as posições ideológicas em conflito.

Especialmente na virada para a década de 1960, esse processo de mudanças se aprofundou com a radicalização e a polarização políticas que se instalaram no país. As divergências passavam desde a concepção de história e o modelo de curso que se desejava até o posicionamento ideológico frente aos eventos políticos marcantes do governo Goulart, tais como o programa para a Reforma Agrária, a Revolta dos Sargentos, a política externa independente, o Comício da Central, para citar apenas alguns pontos (FERREIRA 2008a).

Todos os debates que esses temas envolviam repercutiam intensamente na FNFi e, em especial, no curso de história. Se, nos anos anteriores, as diferentes concepções de história e as visões divergentes sobre o formato dos cursos e as relações entre ensino e pesquisa já se delineavam, a nova conjuntura de intensos debates sobre o lugar da universidade e os usos do ensino de história como instrumento de transformação social provocou, cada vez mais, uma cisão entre alunos e professores, e entre os próprios professores (FERREIRA 2011).

A cadeira de história do Brasil, ocupada por Hélio Vianna, tinha uma postura conservadora, e sua orientação voltava-se para a história política e, principalmente, a história diplomática. O Brasil colonial recebia atenção especial, e as temáticas republicanas ficavam completamente secundarizadas; a abordagem historiográfica era marcada por uma supervalorização dos eventos e dos grandes personagens, sem que a dimensão econômica fosse trabalhada segundo depoimentos de ex-alunos de várias gerações - , e eram profundamente enfadonhas, exclusivamente expositivas, com relatos factuais minuciosos, sem nenhuma indicação bibliográfica e com provas fundamentadas nos conteúdos apresentados em sala de aula, o que requeria apenas uma boa capacidade de memorização. Não havia nenhum estímulo à pesquisa, nem com fontes, nem com bibliografia (FALCON 2009). 
Enquanto Hélio Viana veiculava uma história do Brasil voltada para o passado distante, com ênfase na história política, em especial na valorização do processo de construção da unidade nacional e no destaque do papel dos grandes personagens do panteão nacional, a cadeira de história moderna e contemporânea passou a privilegiar o estudo de períodos mais recentes, com temas sobre história da África, descolonização, e passou a funcionar como um espaço de debate e crítica, e a formar professores com habilidades para fazerem, pesquisas o que não era comum nas outras cadeiras do curso (FALCON 2001).

Os alunos se identificavam cada vez mais com as forças de esquerda, e desejavam um curso que incorporasse a produção do Instituto Superior de Estudos Brasileiros (Iseb), e novas temáticas como história contemporânea da África, o processo de descolonização, as lutas sociais no Brasil.

Nesse contexto, foi criado, em agosto de 1958, o Centro de Estudos de História, e, posteriormente, o Boletim de história (1958-1963). Fundado por iniciativa dos alunos do curso de história, o centro contou com o incentivo e apoio da direção da faculdade e de grande parte dos professores. No entanto, entre 1958 e 1963, ocorreram mudanças de estratégia na publicação: de uma orientação didática do professor do curso secundário, passou-se à crítica do próprio curso universitário, à percepção de suas limitações na formação do profissional de história e à crítica social (PEREIRA 1998).

Ao mesmo tempo em que se delineava uma reestruturação das organizações de esquerda, novas orientações e novos grupos surgiam no país com tendências políticas mais radicais. A penetração do Partido Comunista no meio estudantil ainda que dominante, começava a suscitar críticas e estimular a aproximação com outras orientações de esquerda. A crescente mobilização dos trabalhadores, tanto nas cidades quanto no campo, reivindicando não só melhorias salariais, como também mudanças na estrutura desigual da sociedade, provocavam estímulos para que os estudantes universitários se engajassem de forma mais efetiva nas lutas sociais.

O posicionamento defendido pelos estudantes engajados nas lutas sociais do presente e comprometidos com a necessidade de compreensão do mundo contemporâneo a partir de uma perspectiva brasileira conduzia a uma postura segundo a qual história deveria se envolver com os problemas da atualidade, e o conhecimento histórico deveria apresentar explicações e possíveis soluções (BOLETIM DE HISTÓRIA 1962; 1963).

Para que o ensino de história pudesse ser revisto, a formação do profissional deveria também ser modificada. Os livros didáticos teriam que dar maior atenção ao estudo da história recente do Brasil. O depoimento de Pedro Celso Uchoa Cavalcanti, diretor do Centro de Estudos de História em 1962, expressa com clareza os anseios daqueles jovens universitários: "Para a minha geração, para nós de esquerda, tinham três autores de história: o Caio Prado Jr., o Nelson Werneck Sodré e o Celso Furtado. O resto não tinha importância. Capistrano existia. Mas eram referências para a gente ir buscar coisas, não eram os livros que nos formavam na história do Brasil (CAVALCANTI 2012, p. 10)". 
Com essa perspectiva, os alunos do curso de história ligados ao Centro de Estudos de História rejeitavam os ensinamentos ministrados na maioria das disciplinas oferecidas no curso (com a exceção da cadeira de história moderna e contemporânea), e passavam a ser envolver com o Iseb e a planejar, sob a orientação de Nelson Werneck, a produção de uma coleção de livros didáticos que veio a se chamar "História Nova".

Novamente, é a fala de Pedro Celso Uchoa Cavalcanti que recupera aspectos dessa memória:

O Iseb tinha um curso que era uma confrontação com a Escola Superior de Guerra. O Sodré dava as aulas da segunda-feira: toda segunda-feira, de manhã cedo, eu ia assistir às aulas. [...] Bom, assisti a esse curso do Sodré, [...] fazia perguntas no fim da aula. Ele se interessou por mim. No final do curso, me chamou até na mesa dele e perguntou se eu queria ser assistente dele no Iseb (CAVALCANTI 2012, p. 10).

Estabelecido esse primeiro contato com Nelson Wernenk, o passo seguinte foi a organização de um curso de história para os alunos da FNFi. Dando continuidade ao seu relato, Pedro Celso (2012) declara: "Eu consegui também que o Sodré desse um curso de história do Brasil para colegas meus, ainda da faculdade. Nesse curso, eram 13, 15 pessoas, como Rubens César e outros. Era no Iseb, mas era curso privado. Era um favor que ele estava nos fazendo".

Como desdobramento desse curso, acabou se concretizando o projeto da História Nova, que tinha como enfoque criticar os livros didáticos que existiam, e apresentar uma história do Brasil a partir das contribuições das obras do próprio Werneck Sodré, de Caio Prado e de Celso Furtado. Sob a orientação de Nelson Werneck, teve início a produção dessa coleção de livros didáticos, que tinha o propósito de levar para a educação básica outra visão da história, na qual a dimensão econômica e as lutas sociais desempenhavam um papel-chave. ${ }^{5}$ Assim, ainda que professores como Maria Yeda, com um posicionamento de esquerda, discordassem da concepção de história de Nelson Werneck Sodré, a penetração de suas ideias e das teses marxistas ganhava espaço no FNFi em aberto confronto com as visões há décadas transmitidas por Hélio Viana.

A intensificação do engajamento cada vez maior de alunos e também de professores nos embates políticos travados nos últimos meses do governo Goulart, acerca da reforma da universidade de maneira geral, do curso de história e dos usos do ensino de história como instrumento de transformação social provocou, cada vez mais, uma cisão entre alunos e professores, e entre os próprios professores.

\section{A FNFi na alça de mira: a CPI da UNE}

Os acontecimentos do ano de 1963 foram especialmente importantes nesse processo, ao provocar uma maior radicalização e um aprofundamento das dissensões políticas na FNFi. Nas palavras de Arthur Poerner a FNFi, de 1960 a

\footnotetext{
${ }^{5}$ Ver: LOURENÇO 2008.
} 
1964, foi uma espécie de "escalão avançado do movimento estudantil", sendo vista como a mais politizada das universidades brasileiras (POERNER 2004, p. 188). Desde 1961, com o fim do parlamentarismo e a retomada dos poderes presidenciais de Goulart, as forças de esquerda, sentindo-se vitoriosas, vinham avançando em suas reivindicações, as lutas pelas reformas de base ganhavam nova dimensão, e os movimentos sociais intensificavam suas reivindicações. Nesse contexto, no segundo semestre de 1963, deveriam ser realizadas novas eleições para direção da FNFi.

O então diretor, professor Eremildo Viana, já fora eleito duas vezes, e grande parte dos alunos desejava uma renovação da direção. No entanto, de acordo com os depoimentos orais de antigos professores e alunos, e com as notícias veiculadas pela imprensa, o mestre desejava permanecer no cargo, e trabalhava para atingir tal objetivo. Em resposta, o diretório estudantil mobilizou os estudantes e decretou uma greve que paralisou toda a faculdade. De acordo coma edição de $O$ Jornal de 25 de setembro de 1963,

Os alunos da Faculdade Nacional de Filosofia aguardam a solução prometida pelo Paulo de Tarso, ministro da Educação, em relação à escolha de novo diretor para a Faculdade. [...] Os alunos alegam que a substituição do falecido professor Nilton Campos, na lista tríplice da qual constam ainda os professores Djacir Menezes e Eremildo Viana, pelo professor Kingston é ilegal, já que não houve convocação específica para uma nova eleição (O JORNAL 25/09/1963, p. 11).

Ainda segundo o relato do periódico carioca,

[...] o vice-presidente do Diretório Acadêmico [DA] contou ao Jornal que os alunos resolveram dar um voto de confiança ao ministro da Educação, devido a uma mensagem enviada pelo mesmo ao DA, encerrando assim com a greve. $O$ aluno também declarou que há um pequeno grupo de estudantes que constituem a oposição (GRD), os quais apoiam a reeleição do Eremildo Viana. Sérgio garante que a calma será mantida na Faculdade Nacional de Filosofia, enquanto os alunos aguardam uma resposta do governo (O JORNAL 25/09/1963, p. 11).

Esses relatos expressam os conflitos travados naquele momento e a capacidade dos estudantes de pressionar o Ministério da Educação a atingir seus objetivos, acirrando os ânimos entre professores e alunos.

Paralelamente, na cena nacional, uma Comissão Parlamentar de Inquérito (CPI) fora instituída na Câmara dos Deputados para apurar a infiltração comunista na União Nacional dos Estudantes (UNE) e o uso indevido pela entidade de recursos públicos a fim de promover agitação política. O acompanhamento da CPI nos permite perceber a reprodução dos embates políticos que então marcavam toda a sociedade brasileira. De um lado, as forças de direita conduzindo a CPI e convocando depoentes para comprovar a infiltração comunista na UNE. De outro, os parlamentares de esquerda que visavam neutralizar as investidas de Raimundo Padilha, presidente da CPI, para incriminar os estudantes. 
A FNFi, foco de agitação estudantil, era objeto de investigação, e seu diretor, Eremildo Viana, foi convocado para depor na CPI. O depoimento de Eremildo, publicado de forma resumida em $O$ Jornal, já indicava o posicionamento que o diretor da FNFi começava a assumir. Se, durante vários anos, Eremildo negociou com os estudantes de esquerda e apoiou a constituição do Centro de Estudos de História e o Boletim de história, fornecendo recursos para sua publicação, à medida que o movimento estudantil se radicalizava, seu caminho, como o de muitos outros, tomou a direção oposta. Ainda que o Diário do Congresso não tenha reproduzido a íntegra do depoimento de Eremildo, as matérias de $O$ Jornal e $O$ Globo indicam os principais pontos abordados.

Sob o título "UNE tem verba de sobra para agitar a classe estudantil", O Jornal de 25 de setembro de 1963 assim noticiou o depoimento:

O professor Eremildo Viana argumenta que pelo fato de a UNE possuir verbas vultosas, realiza programas que conturbam a vida estudantil do país ao invés de prestar serviços à Faculdade no campo cultural. [...] Eremildo concorda com o fato de haver a necessidade de reformas nas estruturas políticas e sociais, porém não através da desordem, anarquia e quebra da hierarquia, [...].

Vários episódios de indisciplina e de subversão da ordem são narrados pelo professor Eremildo, e denúncias são feitas da ligação dos estudantes com o Partido Comunista. Como comprovação, o professor ofereceu à Comissão cartazes de caráter subversivo a favor dos sargentos e contra o STF e entregou o Manifesto que orienta a organização dos cursos pré-universitários e suas ligações com o Partido Comunista. [...]

[Segundo o depoente] outro organismo que trama contra a ordem social é o Iseb, aonde alunos expulsos da Faculdade por imoralidade e que não chegaram a concluir seus cursos são professores. ${ }^{6}$

Eremildo relatou episódios antigos e atuais [...] e confirmou trazendo de volta a tona um inquérito administrativo realizado anos antes, sobre bacanais verificadas no prédio da faculdade, onde constam nomes dos alunos [...]. [Disse ainda] que o Conselho Universitário está com o extrato e o relatório do inquérito. Mas não deu qualquer solução (O JORNAL 25/09/1963, p. 5).

Ainda segundo O Jornal, diante dessas últimas declarações, o deputado Padilha solicitou que a "Comissão requeresse à Congregação da Faculdade os nomes dos professores participantes, já que tais nomes foram retirados do processo". Acrescentava ainda o periódico: "Foi requerida a convocação do Reitor Pedro Calmon, já que no processo constam fatos indecorosos" (O JORNAL 25/09/1963, p. 5).

\footnotetext{
${ }_{6}^{6}$ Para um maior detalhamento do relato de Eremildo Viana, seguem trechos publicados de seu depoimento: segundo o depoente, "as reivindicações que os agitadores apresentam e que coincidem com uma decisão de um Congresso realizado em Cuba são: divisão da administração da faculdade com o Diretório Acadêmico, inclusão de 24 representantes estudantis na Congregação, que tem um total de 36 membros, eliminação da exigência de atestado médico ou de comprovante de novo para a inscrição em segunda época, diminuição do grau para aprovação, dispensa de frequência obrigatória; consideram, assim, fundamental a descentralização administrativa de modo a aliviar as responsabilidades do Diretor. [...] [Segundo o depoente] o DA é composto em sua maioria por elementos extremistas, e há um sistema de coação e ameaça para que os alunos opositores das agitações não compareçam às eleições. [O depoente declarou que] mandou um ofício ao reitor da Universidade pedindo que as verbas do DA deste ano fossem bloqueadas, até que, segundo a lei, o dirigente passado, Enilton Sá Rêgo, prestasse contas e apresentasse o balancete, o que se nega fazer" (O JORNAL 25/09/1963).
} 
As declarações de Eremildo na chamada CPI da UNE já indicavam sua guinada em direção às forças que se opunham ao governo Goulart. Também fica evidenciado o clima vigente na FNFi, em que se misturavam denúncias contra alunos e professores por conta de seus posicionamentos políticos e acusações de caráter moral que visavam incriminar e desmoralizar os acusados e comprometê-los com atos tidos como indecorosos.

Nos meses seguintes, o processo de radicalização política se agravou, colocando cada vez mais em campos opostos professores e alunos da FNFi. Nos primeiros meses de 1964, a despeito da resistência do Congresso em avançar na aprovação das reformas de base, Goulart decidiu implementar a Reforma Agrária, adotando como estratégia mobilizar a população para pressionar o Parlamento. Em 13 de março de 1964, o Comício da Central foi um divisor de águas nesse processo. Evidentemente alunos e muitos professores da FNFi participaram ativamente desses momentos finais do governo Goulart, acreditando que a revolução socialista estava por vir. O desfecho dessa história é conhecido. Em 31 de março, o golpe militar decretou o fim do governo Goulart, desencadeando forte repressão contra as forças de esquerda.

$\mathrm{Na}$ FNFi e no curso de história, os episódios que se seguiram foram traumáticos e condicionaram de forma intensa a memória das décadas posteriores. Logo nos primeiros momentos, Eremildo Viana, ajudado por tropas militares, ocupou a Radio MEC, então dirigida por Maria Yedda Linhares, a pretexto de que lá existia um foco de agitação e estavam armazenadas armas para desencadear atos subversivos. Nas semanas que se seguiram, Maria Yedda foi afastada, e Eremildo Viana passou a ocupar seu lugar. Esse episódio marcou profundamente o curso de história, seus alunos e professores, que passaram a encarar Eremildo como o responsável por todo o processo de repressão que se seguiu.

Nos meses seguintes, vários Inquéritos Policiais Militares (IPMs) foram abertos para apurar a infiltração comunista na FNFi, e professores foram acusados e presos, enquanto alunos eram expulsos. De acordo com os dossiês produzidos pelos órgãos de segurança, na FNFI funcionava uma célula comunista que reunia vários professores. As informações reunidas nesses dossiês recuperam eventos e personagens que atuaram na FNFi a partir de 1958, e uma figura destacada nas denúncias feitas por Eremildo, mas também mencionada em outros relatos, é a de Maria Yeda Linhares.

Segundo essa documentação, que pretendia fazer um histórico das ações da esquerda na FNFI, reunindo documentos relativos a diferentes momentos, ${ }^{7}$

\footnotetext{
7 Maria Yedda Linhares era tida "como comunista fanática" e "perigosa" como propagandista de ideias extremistas, mantinha íntimas ligações com João Christovão Cardoso (catedrático de Físico-Química), Darcy Ribeiro, Osvaldo Hurbster de Gusmão e Álvaro Vieira Pinto. Sua atuação "por ordem da célula comunista, era aliciar os alunos do curso de Filosofia - quatro deles (Wanderlei Guilherme dos Santos, Carlos Estevam Martins, Alberto Coelho de Souza e Fausto Guimarães Cupertino)" e "disseminar ideias de subversão contra o então chefe do Departamento de Filosofia, o Sr. Prof. Nilton Campos". "E assim começou o grande motim na FNFI, que culminou em imoralidade por aquela professora que foi acusada, em inquérito, de acobertar atividades indecorosas dos alunos (manter relações íntimas com Alberto Coelho de Souza) [Boletim Reservado, Pasta 23, 3 folhas; 4 fev. 1964; Departamento de Ordem Política e Social - Professores comunistas da FNFI]. Maria Yedda era ainda acusada de "ter convidado para seus instrutores dois comunistas conhecidos: Hugo Weiss (demitido do Colégio Andrews e do Colégio de Aplicação) e Arthur Bernardes Weiss. Os três induzem os alunos à indisciplina para com os professores democratas. Nomeada pelo Ministro Paulo de Tarso diretora da Rádio MEC, por indicação de Darcy Ribeiro, tinha como objetivo de utilizar-se da rádio difusão para disseminar as
} 
Maria Yedda Linhares era tida "como comunista fanática", "perigosa" como "propagandista de ideias extremistas" e acusada de "ter convidado para seus instrutores dois comunistas conhecidos: Hugo Weiss (demitido do Colégio Andrews e do Colégio de Aplicação) e Arthur Bernardes Weiss. Os três induzem os alunos à indisciplina para com os professores democratas. ${ }^{8}$

Constituindo-se a FNFI e alguns de seus professores, na visão dos órgãos de segurança, em um antro de comunistas e de perigosos extremistas, seria um alvo preferencial da repressão. A caça às bruxas estava em vigor, e mais uma vez episódios pontuais do passado, que envolveram alunos e resultaram em inquéritos administrativos para apurar atos tidos como indecorosos, foram acionados para incriminar e desmoralizar professores, acusados de coniventes e participantes de atividades imorais no âmbito da faculdade. ${ }^{9}$

\section{A Comissão de Investigação da Universidade do Brasil}

Exatamente para atingir esse espaço de oposição e de debates foi instaurada, em maio de 1964, uma Comissão de Investigação da Universidade do Brasil, no Rio de Janeiro, para apurar a infiltração comunista na FNFi. Instituída por ordem do senhor ministro da Educação, foi conduzida pelo senhor general Arcy da Rocha Nóbrega e composta pelos professores Mauricio Joppert da Silva e Mauro Ribeiro Viega; a comissão foi acrescida, ainda, dos senhores Adalmyr B. Pinheiro de Barros e do tenente reformado Miguel Uzeda Filho.

De acordo com a documentação arquivada no Dops, constituída também pelo noticiário publicado na imprensa, apesar das suspeitas de existência de uma célula comunista funcionando na FNFi, a comissão não encontrou elementos importantes para a comprovação das acusações feitas aos chamados comunistas da FNFI, tais como Viera Pinto, Maria Yedda Linhares. Mesmo sem ter tido acesso à documentação da comissão, pode-se, pela entrevista de Eremildo Viana concedida à imprensa após a divulgação do seu resultado e de seu dossiê no arquivo do Dops, compreender que as investigações percorreram caminhos inesperados e desapontadores para a repressão. As palavras do próprio Eremildo nos permitem captar o desfecho das apurações: "Enquanto as Comissões de Investigações nas outras Universidades examinaram os fatos em todos os setores, Faculdades e Escolas, a da Universidade do Brasil apenas procurou focalizar a Faculdade Nacional de Filosofia para poder acusar-me". ${ }^{10}$

Eremildo Viana, em seu depoimento arquivado na documentação do Dops, declara "que a comissão foi feita para desmoralizá-lo, para acusá-lo de delator de alunos e professores da faculdade. e de improbidade administrativa". ${ }^{11}$ Ainda

\footnotetext{
ideias que prega na Faculdade" (O JORNAL, 25/09/1963, p. 5). Ver também documentação do Dops, arquivo do Arquivo Publico do Estado do Rio de Janeiro (Aperj), ficha de Maria Yedda Linhares.

8 Ver documentação do Dops, arquivo do Arquivo Publico do Estado do Rio de Janeiro (Aperj), ficha de Maria Yedda Linhares.

9 Ver documentação do Dops, arquivo do Arquivo Publico do Estado do Rio de Janeiro (Aperj), ficha de Maria Yedda Linhares.

${ }^{10}$ Pasta Eremildo Vianna. Informações. Pasta 84 DOPS SI=SFA N0805 (folhas 144-146). Referência: Gabinete do Sr. Diretor.

${ }^{11}$ Ver documentação do Dops, arquivo do Arquivo Publico do Estado do Rio de Janeiro (Aperj), ficha de Maria Yedda Linhares.
} 
de acordo com as suas próprias palavras, Eremildo, incorporando um tom de acusação e de denúncia, "afirma que a Comissão, além de nada apurar contra o reitor e demais membros da Administração Universitária, teria passado a fazer a defesa dos professores e alunos comunistas da Universidade (uma vez que deixara de indiciar conhecidos professores subversivos como Álvaro B. Vieira Pinto, Darcy Ribeiro, Max da Costa Santos". Declara, ainda, que prestou dois depoimentos perante a Comissão e teria entregue documentos que provariam que, a partir de 1962, começou a desenvolver-se uma base comunista na faculdade); ele, então, na condição de Diretor, se opôs tenazmente. ${ }^{12}$

Com essas afirmações, fica evidente que suas queixas, de ter sido acusado injustamente de delator, se tornaram improcedentes na medida em que, mais uma vez, o próprio reafirmava e acusava publicamente a existência de professores comunistas na FNFi.

Os embates entre Eremildo Viana e o general Nóbrega, relativos aos resultados apurados pela comissão da UB, transmitidos diariamente pela grande imprensa carioca, indicam o lugar de importância que a FNFi ocupava na cena política do país naquele momento, e como ainda havia espaços de luta e de alguma garantia de defesa das oposições frente ao arbítrio do regime militar recém-instalado.

Nesse contexto, o funcionamento da FNFi, então dirigida por Faria Goes Sobrinho, ficou em grande parte paralisado, e as atividades docentes ficaram fortemente comprometidas. Somente partir de 1965 o ritmo da FNFi começaria a se regularizar, mas em novas bases, agora sob um regime ditatorial.

\section{Tempos sombrios para a história no IFCS}

Após o Golpe Militar de 1964, o ministério da Educação assumiu a bandeira da Reforma Universitária, e começou a promover mudanças nas universidades federais que foram sendo difundidas para as demais (ABREU 2001).

Em 1965, uma lei federal definiu que a Universidade do Brasil passaria a se chamar Universidade Federal do Rio de Janeiro (UFRJ) e que, a seguir, suas escolas passariam a integrar ou a constituir institutos. O curso de história passaria, assim, a partir de março de 1967, a fazer parte do recém-criado Instituto de Filosofia e Ciências Sociais (IFCS), e teria sua sede na rua Marquês de Olinda, onde já funcionava o Instituto de Ciências Sociais. Nos meses seguintes, o processo de radicalização política atingiu seu auge, com a realização, por órgãos de repressão, de um atentado a bomba ao prédio da Marquês de Olinda, e com a expansão do movimento estudantil, que deflagrou uma onda de greves que paralisaram em grande parte as atividades universitárias.

A despeito de todas essas mudanças, de acordo com os depoimentos de Maria Yedda Linhares e de Francisco Falcon, entre 1965 e 1968 foi possível uma recuperação da dinâmica do curso de história, especialmente nas cadeiras de história moderna e contemporânea e de história da América, já com Eulália Lobo à frente. O próprio crescimento do movimento estudantil a partir de 1966, e 
os questionamentos crescentes do regime militar funcionavam como estímulo ao debate, com a criação de grupos de estudos, seminários e palestras, e o envolvimento com leituras que levavam a uma interpretação da história na perspectiva do materialismo histórico. Ainda nesse período, Maria Yedda tentou criar uma pós-graduação em história social. Chegou a ser elaborado um projeto para o funcionamento do novo curso, mas a iniciativa não vingou. A grade curricular da graduação também não sofreu alterações de monta.

Se, no imediato pós-1964, houve condições de resistência nos escombros da FNFi, então já desmembrada em diferentes institutos, após 1968, os anos de chumbo começariam para valer. Com a decretação do Ato Institucional no 5 (AI5) em dezembro de 1968, houve a cassação de vários professores, e a aplicação do Decreto no 477 para vários alunos.

\section{O novo senhor do IFCS}

Agora transferido para o largo de São Francisco, o curso de história enfrentaria, por vários anos, um clima de denúncia e de perseguição, comprometendo de forma dramática suas atividades. De acordo com os relatórios dos órgãos de segurança, fica evidenciada a importância ganha por Eremildo Viana e o reconhecimento do regime aos seus serviços prestados no combate das atividades ditas comunistas. ${ }^{13}$

Procedidas sindicâncias sobre o professor Eremildo Luiz Vianna, foi apurado que os antecedentes aqui registrados estão corretos quanto às atividades anticomunistas. O epigrafado desenvolveu intensa atividade contra a infiltração comunista que se fazia sentir na FNFi e na UFRJ, no período de 1963 e parte do ano de 1964. No ano de 1963, o marginado prestou depoimento no inquérito aberto no Parlamento para apurar as atividades comunistas na ex-UNE, tendo atuado como testemunha de acusação contra professores e estudantes comunistas. Em vista de sua atuação contra a divulgação e as atividades comunistas na FNFI, foi exonerado do cargo este que exercia desde 1957. Com o advento da Revolução, foi empossado no cargo de Diretor da Rádio Ministério da Educação, cargo que ocupava até 07/69 (FERREIRA 2010).

Esse retrato da trajetória de Eremildo, produzido pelos órgãos de segurança, nos indica os recursos de poder e o cacife que adquiriu para retornar a universidade como o Novo Senhor do curso de história e do IFCS da UFRJ. Tratava-se de atrair novos professores, visto que muitos tinham sido cassados ou atingiam a aposentadoria, como Hélio Viana e Silvio Julio. O regime de cátedra também tinha terminado, mas a forma de ingresso não mudava muito. O recrutamento continuava na base das relações pessoais e de indivíduos que não tinham o chamado "passado politico".

O depoimento de Nara Saleto, que ingressou no curso de história em 1973, dá uma ideia do clima reinante no recém-criado Instituto de Filosofia e Ciências Sociais:

\footnotetext{
${ }_{13}$ Ver Arquivo do Dops. Dossiê Emerildo Viana. Informação no 184/69 da SOB datada de 28 jul. 1969.
} 
Como estou dizendo, os primeiros tempos do IFCS foram terríveis. Havia funcionários espiões, que entravam nas salas de aula a pretexto de ninharias, e seguiam os passos dos professores por toda a parte, até nos elevadores! Eu não podia conversar com os alunos, muito menos convidá-los para ir à minha casa. Eles iam, claro, mas ninguém devia saber: era malvisto, pecaminoso [risos]. A vigilância se estendia dos corredores à cantina, e, se, aos poucos, o clima foi se atenuando, isso se deveu principalmente aos estudantes (FERREIRA 2010).

Nos anos 1970, o projeto de criação de uma pós-graduação em história foi retomado com nova orientação e sob a liderança de Eremildo Viana, mas as dificuldades para a sua consolidação foram muito grandes. O novo curso só viria a poder titular seus alunos a partir da eleição de Eulália Lobo para a coordenação do programa de pós-graduação em 1982. Mas, até lá, muitos passos seriam dados.

Foram o processo de abertura política iniciado com o governo Geisel (19741979) e o avanço das lutas pela anistia que trouxeram novos tempos para o IFCS e para o curso de história, com a plena reintegração dos docentes cassados em 1979. Entre os professores do curso de história nessa situação estavam Eulália Lobo, Hugo Weiss, já falecido na ocasião, Manoel Maurício de Albuquerque, e Maria Yedda Linhares.

\section{Considerações finais}

Cabe destacar, por fim, que os debates e os desdobramentos dos eventos ocorridos na década aqui enfocada (1958-1968) revelam-se fundamentais para se compreender os movimentos sucessivos que tiveram lugar no território pouco pacífico de desenvolvimento dos cursos universitários de história. Certamente, uma investigação ampliada de diferentes aspectos aqui tratados, tais como a trajetória dos professores e dos alunos, suas relações com os debates internacionais que foram mencionados, e os conflitos entre concepções de história distintas podem contribuir para o delineamento de uma perspectiva mais histórica dos nossos cursos de história, especialmente em um momento em que a regulamentação do oficio de historiador está em discussão. Merece destaque igualmente a importância e as possibilidades do estudo acerca das memórias de eventos traumáticos e a repressão desencadeada na FNFi/IFCS. Uma análise dos depoimentos dos alunos e professores coletados para essa pesquisa nos permite destacar alguns pontos importantes.

Como sabemos, os depoimentos orais são memórias que representam diferentes versões do passado e expressam lembranças contraditórias, esquecimentos, distorções, conflitos, e não podem ser tomados como relatos "verdadeiros" e "objetivos" sobre os fatos narrados; mas, ainda assim e por isso mesmo, nos permitem o acesso a um rico material e a informações pouco encontradas em outras fontes. Os relatos obtidos se revestiram de grande relevância como chave e ponto de partida para mapear questões a serem pesquisadas num emaranhado de documentos, dispersos e fragmentados. Além de preencher muitas lacunas que a documentação escrita não conseguia suprir, 
os relatos orais foram caminhos seguros e ricos para esclarecer as disputas e conflitos de memórias, e para nos fornecer pistas para compreender as versões construídas sobre a trajetória dos cursos. O foco central dos depoimentos concentrou-se nas lutas políticas, em especial do final dos anos 1950 até 1964, mais do que no conteúdo dos cursos em si mesmos, considerando que a maioria dos depoentes ingressou na universidade a partir de 1957/1958 e, por conseguinte, muito de suas vivências privilegiaram os anos de radicalização política no Brasil, a partir do governo JK até a queda de Jango, com o Golpe Militar de 1964. O que se pode perceber é que o engajamento dos alunos e professores nos projetos de transformação do Brasil, ainda que de diferentes maneiras e com orientações políticas distintas, condicionaram fortemente as memórias sobre o curso de história, colocando no esquecimento fatos positivos para destacar a repressão e os traumas que o Golpe Militar provocou.

\section{Referências bibliográficas}

ABREU, Alzira Alves de et al. (org.). Reforma universitária. In:

Dicionário histórico-biográfico brasileiro pós-1930. Rio de Janeiro: FGV, 2001. V. 4.

AMADO, Janaína; FERREIRA, Marieta de Moraes (org.). Usos e abusos da história oral. Rio de Janeiro: FGV, 1998.

BITTENCOURT, Raul. Breve histórico da Universidade do Brasil e da FNFi. Digesto da Faculdade Nacional de Filosofia, Rio de Janeiro, 1955.

BOLETIM DE HISTÓRIA. Crítica das revistas. Boletim de História, Centro de Estudos de História, Faculdade Nacional de Filosofia, Universidade do Brasil, Rio de Janeiro, v. 1-2, n. 4-5, p. 189-193, jul.-set./out.-dez. 1959a. . Um pouco de luz sobre a educação no Brasil e suas causas. Boletim de História, Centro de Estudos de História, Faculdade Nacional de Filosofia, Universidade do Brasil, Rio de Janeiro, v. 1, n. 2/3, p. 133-145, jan.-mar./ abr.-jun. 1959b.

. I Congresso de Professores do Ensino Médio. Boletim de História, Centro de Estudos de História, Faculdade Nacional de Filosofia, Universidade do Brasil, Rio de Janeiro, ano III, n. 6, p. 195-197, jan. /jun., 1961 a.

Didática da história. Boletim de História, Centro de Estudos de História, Faculdade Nacional de Filosofia, Universidade do Brasil, Rio de Janeiro, v. 3, n. 6, p.161-171, jan./jun., 1961b.

. Reforma universitária e escola pública. Editorial. Boletim de História, Centro de Estudos de História, Faculdade Nacional de Filosofia, Universidade do Brasil, Rio de Janeiro, v.3, n. 6, p. 7-9, jan.-jun. 1961c.

Conselho Federal de Educação. Didática da história. Boletim de História, Centro de Estudos de História, Faculdade Nacional de Filosofia, Universidade do Brasil, Rio de Janeiro, v. 5, n. 7, p. 151-155, ago. 1963. 
BOMENY, Helena. A Reforma Universitária de 1968: 25 anos depois. RBCS, Associação Nacional de Pós-Graduação e Pesquisa em Ciências Sociais, São Paulo, v. 26, s.d. Disponível em: www.anpocs.org.br/portal/publicacoes/ rbcs_00_26/rbcs26_04.htm. Acesso em: 5 jun. 2011.

BOUTIER, Jean; CLAUDE PASSERON, Jean; REVEL, Jacques (dirs). Qu'est-ce qu'une discipline?. Paris: Esquête, 2006.

CALMON, Pedro. História do Brasil: programa de cultura, consciência e patriotismo. In: Anais Simpósio de professores de história do ensino superior, 1. Marília: Associação Nacional de História, 2010.

CAPELATO, M.H ; FERLINI, Vera Lúcia; GLEZER, Raquel. A escola uspiana de história. Estudos Avançados, Instituto de Estudos Avançados da USP, São Paulo, v. 8, n. 22, 1994.

CHARLE, Christophe. La Republique des universitaires:1870-1940. Paris: Seuil, 1979.

CLARK, Terry. Prophets and patrons: the French university and the emergence of the social sciences. Cambridge: Harvard University Press, 1973.

CORRÊA, Serzedello. Nota de capa. Boletim de História, Centro de Estudos de História, Faculdade Nacional de Filosofia, Universidade do Brasil, Rio de Janeiro, v. 5, n. 7, ago. 1963.

CÔRTES, Norma. A democracia educa. In: PAIVA, Vanilda; SENTO-SÉ, João Trajano (org.). Pensamento social brasileiro. São Paulo: Cortez, 2005. p. 151-173.

DUMOULIN, Olivier. Profession historien. Paris, 1983. Tese (Doutorado em História) - EHESS, Paris, 1983.

ESTE BOLETIM. Boletim Informativo da Associação dos Professores Universitários de História, Marília, v. 1, n. 1, p. 1, jan./out. 1962.

FALCON, Francisco José Calazans. O I Simpósio dos professores de história do ensino superior. Boletim de História, Centro de Estudos de História, Faculdade Nacional de Filosofia, Universidade do Brasil, Rio de Janeiro, v. 5, n. 7, p. 187-196, ago. 1963a.

. O II Simpósio dos Professores Universitários de História. Boletim de História, Centro de Estudos de História, Faculdade Nacional de Filosofia, Universidade do Brasil, Rio de Janeiro, v. 5, n. 7, p. 197-203, ago. 1963b.

A cadeira de história moderna e contemporânea. In: SILVA, Francisco Carlos Teixeira da; MATTOS, Hebe; FRAGOSO, João (org.). Escritos sobre a história da educação: homenagem à Maria Yedda Leite Linhares. Rio de Janeiro: Mauad/Faperj, 2001.

. Memória e história: a fundação da Anpuh. São Paulo, 2011. In Anais

Simpósio da Anpuh. São Paulo: USP, 2011. Mimeo. 
FÁVERO, Maria de Lourdes de Albuquerque. Universidade e poder. Rio de Janeiro: Achiamé, 1980.

. A universidade no Brasil: das origens à reforma universitária de 1968. Educar, Editora UFPR, Curitiba, n. 28, p. 17-36, 2006. Disponível em: www.scielo.br/pdf/er/n28/a03n28.pdf. Acesso em: 11 dez. 2011.

FERREIRA, Marieta de Moraes. Entrevista com Maria Yedda Linhares. Estudos Históricos, Rio de Janeiro, Cpdoc/FGV, v. 5, n. 10, p. 216-250, 1992. Disponível em: www.cpdoc.fgv.br/revista/arq/105.pdf. Acesso em: 20 nov. 2006.

; CASTRO, Celso Corrêa Pinto de; OLIVEIRA, Lúcia Lippi. Entrevista com Gilberto Velho. Estudos Históricos, Rio de Janeiro, Cpdoc/FGV, n. 28, 2001a. Disponível em: www.cpdoc.fgv.br/revista/arq/316.pdf. Acesso em: 16 mar. 2007.

- A cadeira de história moderna e contemporânea: um espaço de crítica e renovação do ensino da história. In: SILVA, Francisco Carlos Teixeira da; MATTOS, Hebe; FRAGOSO, João (org.). Escritos sobre história e educação: homenagem à Maria Yedda Linhares. Rio de Janeiro: Mauad/ Faperj, 2001b, p. 553-568.

- Notas sobre a institucionalização dos cursos universitários de história do Rio de Janeiro. In: GUIMARÃES, Manuel Luiz Salgado (org.). Estudos sobre a escrita da história. Rio de Janeiro: 7 Letras, 2006, p. 139-161.

Perfis e trajetórias dos professores universitários de história no Rio de Janeiro. In: OLIVEIRA, Antônio J. Barbosa (org.). Universidade: lugares de memória. Rio de Janeiro: UFRJ/Fórum de Ciência e Cultura/Sistema de Biblioteca e Informações, 2008a.

. Entrevista com Francisco Falcon. 2008b. CPDOC. FGV. Mimeo.

. Entrevista com Nara Saleto. 2010. CPDOC/FGV. Mimeo.

. Demandas sociais e história do tempo presente. In: VARELLA, Flávia; MOLLO, Helena; PEREIRA, Mateus; DA MATA, Sérgio (org.). Tempo presente \& usos do passado. Rio de Janeiro: Editora FGV, 2012a, p. 101-124.

. Entrevista com Pedro Celso Uchoa Cavalcanti. 2012b. CPDOC/FGV. Mimeo.

. Entrevista com Ilmar R Mattos. 2012c. CPDOC/FGV. Mimeo.

GOMES, Angela de Castro. A República, a história e o IHGB. Belo Horizonte: Fino Traço, 2012.

História e historiadores: a política cultural do Estado Novo. Rio de Janeiro: FGV, 1996.

GONTIJO, Rebeca. Capistrano de Abreu, viajando. Revista Brasileira de História, São Paulo, v. 30, n. 59, p 15-36, 2010. 
GRINBERG, Keila. O olhar do historiador. Revista Ciência Hoje, Coluna Em Tempo, n.p., 14 dez. 2012. Disponível em: http://cienciahoje.uol.com.br/ colunas/em-tempo/por-um-olhar-do-historiador. Acesso em: dez. 2012.

GUIMARÃES, Lúcia Maria Paschoal. Da escola palatina ao silogeu: Instituto Histórico e Geográfico Brasileiro (1889-1938). Rio de Janeiro: Museu da República, 2007.

GUIMARÃES, Manoel Luís Salgado. Entre amadorismo e profissionalismo: as tensões da prática histórica no século XIX. Topoi, Rio de Janeiro, n. 5, p. 184-200, set. 2002.

. Estudos sobre a escrita da história. Rio de Janeiro: 7 Letras, 2007.

HOLLANDA, G. de. Um quarto de século de programas e compêndios de história para o ensino secundário brasileiro, 1931-1956. Rio de Janeiro: Inep/Ministério da Educação, 1957.

KEYLOR, Willian. Academy and community: the foundation of the French historical profession. Cambridge: Harvard University Press, 1975.

- O lugar das disciplinas pedagógicas no curso de história. In: Anais Simpósio de professores de história do ensino superior, 1. Marília: Associação Nacional de História, 2010.

LOURENÇO, Elaine. História Nova do Brasil: revisitando uma obra polêmica. Revista Brasileira de História, v. 28, n. 56. São Paulo, 2008, p. 385-406.

MATTOS, Ilmar Rohloff (org.). Histórias do ensino da história no Brasil. Rio de Janeiro: Access, 1999.

MONTEIRO, Ana Maria et al. (org.). Qual o valor da história hoje? Rio de Janeiro: Editora FGV, 2012.

NOIRIEL, Gérard. Naissance du métier d'historien. Genêses, n. 1, Set., 1990.

PEREIRA, Daniel Mesquita. Boletim de história: uma experiência de vanguarda na Faculdade Nacional de Filosofia - 1958/1963. Rio de Janeiro, 1998. Dissertação (Mestrado em História) - Departamento de História, Pontifícia Universidade Católica do Rio de Janeiro, Rio de Janeiro, 1998.

PINTO, Álvaro Vieira. Ideologia e desenvolvimento nacional. Rio de Janeiro: Iseb, 1959.

POERNER, Arthur. O poder jovem: história da participação política dos estudantes desde o Brasil Colônia até o governo Lula. 5. ed. Rio de Janeiro: Booklink, 2004.

ROIZ, Diogo da Silva. Caminhos e descaminhos do ensino de história. São Paulo: Appris, 2012.

SCHWARTZMAN, Simon. Universidade brasileira: organização e problemas. Ciência e Cultura, v. 37, n. 7, p. 229-234, jul. 1985. Suplemento especial. 
SODRÉ, Nelson Werneck. Formação histórica do Brasil. São Paulo: Brasiliense, 1962.

UNE tem verba de sobra para agitar a classe estudantil. O Jornal, 25/09/1963.

VAINFAS, Ronaldo; GOMES, Ângela de Castro. Entrevista com Eulália Maria Lahmeyer Lobo. Estudos Históricos, Rio de Janeiro, Cpdoc/FGV, v. 5, n. 9, p. 84-96, 1992. Disponível em: www.cpdoc.fgv.br/revista/arq/96.pdf. Acesso em: 16 mar. 2007.

VIANA, Eremildo Luiz. Matérias complementares e auxiliares e o alargamento do horizonte no estudo da História. In: Anais Simpósio de professores de história do ensino superior, 1. Marília: Associação Nacional de História, 2010.

VIANNA, Hélio. História do Brasil. 4a ed. São Paulo: Melhoramentos, 1966.

WEISS, Hugo. Semana de Estudos Americanos. Boletim de História, Centro de Estudos de História, Faculdade Nacional de Filosofia, Universidade do Brasil, Rio de Janeiro, v. 1, n. 2/3, p. 147-159, jan./jun. 1959.

Acervos documentais consultados

Arquivo Gustavo Capanema (Centro de Pesquisa e Documentação em História Contemporânea do Brasil da Fundação Getulio Vargas - Cpdoc/FGV).

64 Fundo Hélio Viana (Instituto Histórico e Geográfico Brasileiro - IHGB).

Arquivo Faculdade Nacional de Filosofia (Programa e Estudos e Documentação Educação e Sociedade - Proedes/UFRJ).

Arquivo do IFCS/UFRJ - Documentação dos professores Eremildo Viana, Hélio Viana e Marina Delamare São Paulo de Vasconcellos

Arquivo do Dops - Arquivo Público do Estado do Rio de Janeiro (Aperj). Dossiês de Eremildo Viana, Maria Yedda Linhares, Eulália Lobo, Pedro Celso Uchoa Cavalcanti, Faculdade Nacional de Filosofia. 